\title{
ÓLEO DE RESÍDUOS DA FILETAGEM DE TILÁPIA (Oreochromis niloticus) PARA PRODUÇÃO DE BIODIESEL
}

\author{
Guilherme Cleto Carvalho* \\ Renato Silva Leal ${ }^{* *}$ \\ Bruno Olivetti de Mattos*** \\ Thiago dos Santos Tristão ${ }^{* * * *}$ \\ Jeicielle Pereira Macedo*****
}

Maria Emília de Sousa Gomes Pimenta******

RESUMO: O objetivo deste trabalho foi avaliar o potencial dos óleos extraídos dos resíduos da filetagem de tilápia, para produção de biodiesel, selecionando o que apresentou maior potencial. Para tanto, foram extraídos os óleos brutos de cabeças, carcaças e vísceras os quais passaram por análises físico-químicas e de rendimento. Utilizou-se um DIC, com três tratamentos (cabeça, carcaça e víscera) e cinco repetições para análise estatística dos dados. Observaram-se diferenças significativas para os óleos $(P<0,05)$ e o óleo de vísceras apresentou maior rendimento. Por esse motivo, este óleo foi selecionado para os estudos posteriores. Nessa nova etapa do trabalho, os tratamentos foram constituídos por óleo bruto neutralizado e óleo refinado de vísceras, com diferentes volumes de $\mathrm{NaOH}$ 16\%. Empregou-se um DIC, num fatorial $2 \times 3$, com três repetições, para análise estatística. As variáveis analisadas foram índice de acidez, índice de saponificação, índice de peróxido e índice de iodo. Avaliou-se, ainda, o rendimento de todos os biodieseis obtidos. Concluiu-se que o óleo que mais se adequou à produção de biodiesel em razão do alto rendimento e atendeu às normas da ANP foi o óleo de vísceras.

PALAVRAS-CHAVE: Biocombustíveis; Índice de acidez; Neutralização; Qualidade do biodiesel.

\footnotetext{
Mestre em Ciências Veterinárias, Universidade Federal de Lavras (UFLA), Departamento de Medicina Veterinária, Lavras, MG, Brasil

** Doutor em Ciência dos Alimentos, Docente da Universidade do Estado de Minas Gerais (UEMG), Belo Horizonte, MG, Brasil

*** Doutor em Zootecnia, Docente Permanente do Programa de Pós-graduação em Aquicultura da Universidade Nilton Lins - (UNINILTON Lins), Manaus, AM, Brasil. E-mail: mattos.bo@gmail.com

**** Graduando em Engenharia Química, Universidade Federal de Lavras (UFLA), Lavras, MG, Brasil

${ }^{* * * * *}$ Química, Centro Universitário de Lavras (UniLavras), Departamento de Química, Lavras, MG, Brasil

${ }^{* * * * * *}$ Doutora em Zootecnia, Docente Adjunta da Universidade Federal de Lavras (UFLA), Departamento de Ciência dos Alimentos, Lavras, MG, Brasil
} 


\title{
RESIDUAL OIL FROM THE FILLETING OF TILAPIA (Oreochromis niloticus) FOR BIODIESEL PRODUCTION
}

\begin{abstract}
The potential of oils extracted from tilapia filleting wastes for the production of biodiesel is analyzed. Crude oils, extracted from heads, carcasses and viscera, were analyzed for physical, chemical and yield factors. DIC with three treatments (heads, carcasses and viscera) and five replications were employed for the statistical analysis of data. There were significant differences in oils $(p<0.05)$. Since viscera oil had the highest yield rate, it was selected for further studies. Later, treatments comprised neutral crude oil and refined oil from viscera, with different volumes of $\mathrm{NaOH} 16 \%$. DIC, $2 \times 3$, with three replications was applied for statistical analysis. Variables comprised acidity index, saponification index, peroxide index and iodine index. Yield of all types of biodiesel obtained were assessed. Oil from viscera was the most adequate oil for the production of biodiesel due to its high yield and compliance to ANP norms.
\end{abstract}

KEY WORDS: Biofuel; Acidity index; Neutralization; Quality of biodiesel.

\section{INTRODUÇÃO}

Os resíduos sólidos do processamento de peixe são destinados principalmente à alimentação animal, em espécies como a tilápia, esses valores podem alcançar até 70\% do volume produzido (VIDOTTI; GONÇALVES, 2006). Esse resíduo constitui uma alternativa a mais na matriz energética para obtenção de diferentes subprodutos da cadeia produtiva do pescado (AGUIAR; GOULART, 2014). Além disso, seu aproveitamento é ecologicamente recomendável, em razão da alta carga de matéria orgânica que seria descartada no ambiente (BOSCOLO; ALDI, 2007).

Com o crescimento das indústrias de processamento da tilápia, no Brasil, observa-se que a quantidade de resíduos gerados por esta atividade é cada vez maior. No mundo, esta atividade gera um montante de 66,5 milhões de toneladas métricas de resíduos, por ano, que ocasionam vários problemas econômicos, ambientais e sociais (MORAIS et al., 2001; SILVA et al., 2012). Atualmente, as vísceras são, muitas vezes, descartadas pela maioria dos piscicultores. Os resultados demonstram que 
o óleo de peixe é uma alternativa para a produção de biodiesel, no Brasil, já que possibilita a utilização de matérias-primas que são bem escassas em algumas regiões do país (FELTER et al., 2010).

Atualmente os óleos provenientes de resíduos agroindustriais podem ser utilizados na alimentação humana e animal, embora seu uso pela indústria de biocombustíveis é crescente em comparação à gordura animal, 83\% x 17\% (ANP, 2008), sobretudo no início dos anos 2000, pelo processo de transesterificação do biodiesel (GUNSTONE, 2011).

O investimento em combustíveis alternativos se destacou nos anos de 2006 a 2011 (OLIVEIRA; RAMALHO, 2006), motivado pelos elevados preços do petróleo, pela elevada demanda de energia (FGV, 2012) e por problemas ambientais, como o aquecimento global. Dessa forma, combustíveis a diesel são de importância para o setor econômico de um país em desenvolvimento (GERIS et al., 2007). O desenvolvimento de combustíveis renováveis, que minimizem os problemas ambientais instiga a procura por combustíveis alternativos aos derivados de petróleo. $\mathrm{O}$ interesse por recursos naturais, como fontes lignocelulósicas ou lipídicas, apresentam alternativas para a produção de biocombustíveis (DABDOUB et al., 2009).

Neste contexto, o biodiesel, motivado por fatores ambientais, econômicos e sociais (KOIKE et al., 2010), apresenta-se como um potencial para a substituição parcial do petrodiesel (SILVA; FREITAS, 2008), pois é produzido por fontes renováveis como óleos vegetais e gorduras animais, é biodegradável e seus níveis de emissão de poluentes são inferiores aos associados a derivados fósseis (KRAWCZYK,1996; GARCIA; VON-SPERLING, 2010). O biodiesel, além de ser de baixo custo, tem a vantagem de ser renovável e possui nível de biodegradabilidade maior que o diesel (BARROS et al., 2008). A possibilidade de ocorrência de chuvas ácidas ocasionadas pela combustão do biodiesel é reduzida uma vez que este combustível possui teor de enxofre 400 vezes menor que o encontrado no diesel oriundo do petróleo, e seu processamento não produz resíduos poluentes (BARROS et al., 2008).

Um dos principais componentes deste processo é o conteúdo de lipídeos, os quais podem ser separados originando o óleo de pescado. Tal óleo constitui importante fonte de ácidos graxos polinsaturados (AGPI) essenciais, principalmente da série ômega 3 (principais ácidos da série: 18:3 ácido linolênico; 20:5 ácido 
eicosapentaenoico; 22:6 ácido docosa-hexaenoico) (MORAIS et al., 2001; CUNHA et al., 2009).

Pesquisas nessa área são escassas, mesmo pelo elevado potencial para o uso do óleo de pescado como biodiesel, uma vez que esse óleo é constituído por ácidos graxos de cadeia longa responsável por proporcionar maior índice de cetano no biodiesel produzido e a consequente melhoria no desempenho do motor a diesel e menor emissão de poluentes (REYES; SPULVEDA, 2006; LIN; LIN, 2006; 2009).

Portanto, os objetivos deste trabalho foram avaliar o potencial dos óleos extraídos dos resíduos da filetagem de tilápia para produção de biodiesel, selecionar aquele que apresente um potencial maior para esse fim e caracterizar o biodiesel obtido desse óleo.

\section{MATERIAL E MÉTODOS}

Este trabalho foi realizado em duas etapas, sendo a primeira a obtenção e caracterização dos óleos de diferentes resíduos da filetagem de tilápias e a segunda a elaboração e caracterização do biodiesel obtido pelo óleo de vísceras de tilápia. Etapa 01:

\subsection{OBTENÇÃO DOS RESÍDUOS DA FILETAGEM DE TILÁPIAS}

A matéria-prima para obtenção do óleo e posterior produção do biodiesel foi constituída dos resíduos da filetagem das tilápias, obtidas na piscicultura Cristalina, localizada no município de Fartura, no Estado de São Paulo. As tilápias produzidas, nesse local, são processadas na propriedade e possuem o selo de inspeção federal SIF.

\subsection{PREPARAÇÃO DOS RESÍDUOS DA FILETAGEM DE TILÁPIAS E OBTENÇÃO DOS ÓLEOS BRUTOS}

Os resíduos foram separados em cabeças, carcaças e vísceras, embalados a vácuo e transportados em estado congelado $\left(-5^{\circ} \mathrm{C}\right)$, em caixas térmicas com gelo 
até a Planta Piloto de Processamento de Pescado onde foram armazenados em freezer horizontal a $-18^{\circ} \mathrm{C}$, no Departamento de Ciência dos Alimentos (DCA), da Universidade Federal de Lavras (UFLA).

O primeiro passo constituiu na preparação dos diferentes resíduos, a saber: retirada do couro das cabeças e retirada das nadadeiras das carcaças. As vísceras foram utilizadas integralmente. As cabeças e carcaças limpas foram moídas em moedor de carne (CAF 10 SM Inox). Dando sequência ao processo de obtenção dos diferentes óleos brutos, estes foram misturados às massas obtidas dos resíduos de cabeças, carcaças e vísceras, na razão 1:1, água destilada. Somente as vísceras foram batidas em liquidificador industrial até a obtenção de uma massa homogênea. Em seguida, cada conjunto de resíduo obtido foi levado ao banho-maria à temperatura constante de $60^{\circ} \mathrm{C}$, por um período de 60 minutos. Após este processo, cada conjunto foi peneirado, para retenção dos sólidos e, em seguida, centrifugados a $10.000 \mathrm{rpm}$ durante 15 minutos. Após a separação das fases aquosa e oleosa, a fase oleosa foi recolhida e armazenada em frasco de vidro âmbar com a finalidade de proteger o óleo contra os efeitos da luz.

\subsection{ANÁLISES FÍSICO-QUÍMICAS E DE RENDIMENTO DOS ÓLEOS BRUTOS OBTI- DOS DOS DIFERENTES RESÍDUOS DA FILETAGEM DE TILÁPIA}

Os três diferentes óleos brutos obtidos da carcaça, cabeça e víscera foram analisados físico-quimicamente quanto ao índice de iodo, saponificação, índice de acidez, índice de peróxido e densidade, segundo AOCS (2004).

O rendimento em óleo bruto de tilápia obtido, após o processamento dos diferentes resíduos, foi calculado tendo como referência a massa do óleo (mo) e a massa de resíduo $(\mathrm{mr})$. Com isso, o valor do rendimento do processo reacional foi obtido mediante a equação:

$$
R=\left(\frac{m o}{m r}\right) \times 100
$$

Em que: $\mathrm{R}=$ rendimento do resíduo em óleo, em \%; mo = massa do óleo em $\mathrm{g} ; \mathrm{mr}=$ massa do resíduo em $\mathrm{g}$. 
2.4 ELABORAÇÃO E CARACTERIZAÇÃO DO BIODIESEL UTILIZANDO ÓLEO BRUTO E REFINADO DE VÍSCERAS DE TILÁPIA

Tendo em vista que o óleo bruto de víscera apresentou o maior rendimento, este foi utilizado para a produção de biodiesel, porém, por algumas limitações, para produção do biodiesel, tornou-se necessário avaliar diferentes formas de obtenção do biodiesel com base no óleo bruto neutralizado e do óleo refinado.

O óleo bruto neutralizado foi obtido em testes preliminares pela adição de diferentes volumes de hidróxido de sódio $(\mathrm{NaOH})$ 16\% (5 mL , $6 \mathrm{~mL}$ e $7 \mathrm{~mL}$ ). Em seguida, o óleo foi refinado, de acordo com metodologia adaptada descrita por Cunha et al. (2009), com base no refino químico ou alcalino que consiste na filtração, degomagem, neutralização, lavagem e desumidificação.

Este processo visou à remoção de fosfolipídios (também denominados de fosfatídios), proteínas e substâncias coloidais do óleo bruto, além da eliminação de outras impurezas, como sabões e íons metálicos. Estes componentes devem ser removidos, para evitar a sua precipitação, durante a estocagem do óleo. A remoção dessas substâncias reduz o consumo de álcali no processo de neutralização.

\subsection{TRANSESTERIFICAÇÃO}

A reação de transesterificação foi aplicada para a produção do biodiesel, obtido por meio do óleo bruto neutralizado e óleo refinado.

Todas as reações de transesterificação foram realizadas em balões de fundo redondo de duas bocas de $250 \mathrm{~mL}$. Os óleos foram colocados em Erlenmyer de 250 $\mathrm{mL}$, a reação de transesterificação foi realizada em presença de catalisador solução de hidróxido de sódio em metanol, utilizando razão molar de 5:1 de óleo:álcool na presença de $1 \%$ de catalisador. O reagente foi adicionado, lentamente, ao óleo de peixe em agitação mecânica e temperatura constante de $60^{\circ} \mathrm{C}$, em agitador magnético, o tempo de reação foi de 20 minutos. Após o tempo de reação, a mistura foi levada, para funil de separação, para descanso de 12 horas. Durante o processo de separação, o glicerol por ser mais denso depositou-se na parte inferior do funil e o biodiesel na parte superior, sendo as duas fases recolhidas separadamente. 


\subsection{ANÁLISES FÍSICO-QUÍMICAS E DE RENDIMENTO DO BIODIESEL}

O biodiesel obtido do óleo neutralizado e o óleo refinado de vísceras de tilápia foram analisados físico-quimicamente quanto ao índices de iodo, saponificação, índice de acidez, índice de peróxido e densidade, segundo AOCS (2004).

$\mathrm{O}$ rendimento em biodiesel de vísceras de tilápia foi calculado tendo como referência o volume do óleo de vísceras (vo) e o volume do biodiesel (vb). Com isso, o valor do rendimento do processo reacional foi obtido mediante a equação:

$$
R=\left(\frac{v o}{v b}\right) \times 100
$$

em que: $\mathrm{R}=$ rendimento de biodiesel, em \%; vo = volume do óleo de tilápia em $\mathrm{mL} ; \mathrm{vb}=$ volume de biodiesel em $\mathrm{mL}$.

\subsection{ANÁLISE ESTATÍSTICA}

Para análise estatística dos dados obtidos referentes aos diferentes óleos brutos, foi empregado o delineamento estatístico, inteiramente casualizado, com três matérias-primas (óleo de cabeça, carcaça e vísceras) e cinco repetições. As médias foram submetidas à análise de variância (Anova) e comparadas pelo teste de Tukey, em nível de 5\% de significância. Com base nos resultados obtidos, foi selecionado o óleo bruto que proporcionou o maior rendimento e potencial para produção do biodiesel.

Para avaliação dos diferentes biodieseis obtidos de óleo neutralizado e óleo refinado de vísceras de tilápia, foi empregado o delineamento experimental, inteiramente casualizado, em um fatorial 2x3 (tipo de óleo: óleo neutralizado e óleo refinado x volume de $\mathrm{NaOH}, 5 \mathrm{~mL}, 6 \mathrm{~mL}$ e $7 \mathrm{~mL}$ ) com três repetições. As médias foram submetidas à análise de variância (Anova). O software utilizado foi IBM SPSS Statistics para Windows, versão 20.0 (IBM. Corp Amonk, NY, EUA). 


\section{RESULTADOS E DISCUSSÃO}

3.1 CARACTERÍSTICAS FÍSICO-QUÍMICAS E RENDIMENTO DE ÓLEO BRUTO OBTIDO DE DIFERENTES RESÍDUOS DA FILETAGEM DE TILÁPIAS

O óleo bruto obtido de diferentes resíduos da filetagem de tilápia foram submetidos às análises físico-químicas para avaliar sua qualidade e viabilidade no uso como biocombustível.

\section{2 ÍNDICE DE ACIDEZ}

Encontram-se na Tabela 1 os índices de acidez dos óleos brutos, obtidos de diferentes resíduos da filetagem de tilápia.

Tabela 1. Índice de acidez (mg KOH/g) dos óleos brutos de cabeça, carcaça e vísceras obtidos dos resíduos da filetagem da tilápia

\begin{tabular}{cc}
\hline Especificação das amostras & Índice de acidez $(\mathrm{mg} \mathrm{KOH} / \mathrm{g})$ \\
\hline Óleo de cabeça & $1,86 \pm 0,01 \mathrm{~B}$ \\
Óleo de carcaça & $0,26 \pm 0,01 \mathrm{C}$ \\
Óleo de víscera & $56,91 \pm 0,18 \mathrm{~A}$ \\
\hline
\end{tabular}

*Médias na mesma coluna com letras diferentes são diferentes significativamente pelo teste de Tukey.

Houve diferença significativa $(P<0,05)$ entre os índices de acidez dos diferentes óleos e o óleo de víscera apresentou o maior índice 56,91 e o óleo da carcaça o menor índice 0,26 . Esses resultados sugerem que o óleo de víscera se encontrava em estado avançado de deterioração. De acordo com Fernando et al. (2007), o índice de acidez informa quanto há de ácidos graxos livres provenientes dos triacilglicerois hidrolisados na amostra original. A conservação do óleo, também, foi indicada por este índice e a decomposição dos glicerídios foi acelerada por aquecimento e pela luz, e a rancidez é quase sempre acompanhada pela formação de ácido graxo livre. Essa degradação está diretamente ligada às enzimas presentes, 
no conteúdo visceral, que acelera o processo de degradação dos lipídios. O índice de acidez elevado tem efeito negativo para o processo de produção de biodiesel, exigindo quantidade maior de catalisador para que ocorra a reação. Dessa forma, é necessário que o óleo de vísceras de tilápia seja neutralizado para posterior produção do biodiesel (VALLE et al., 2011). Estudos de Gomes et al. (2011) mostraram valores médios para índice de acidez de óleo de tilápia extraído por cocção e prensagem de 7,6 mg KOH/g. Já Valle et al. (2011) realizaram comparação da acidez do óleo de tilápia, utilizando peixes com e sem seleção de vesícula biliar e outras matérias não adiposas. Os resultados mostraram que o índice de acidez foi de $7,14 \mathrm{mg} \mathrm{KOH} / \mathrm{g}$, para o óleo sem seleção e de $0,65 \mathrm{mg} \mathrm{KOH} / \mathrm{g}$, para o óleo de vísceras selecionadas.

Em outro estudo, Araújo (2011) verificou que o óleo bruto, extraído em condições quentes, apresentou índice de acidez maior em comparação aos resultados do óleo extraído a frio, obtido por meio de prensagem, que foi de $1,29 \mathrm{mg} \mathrm{KOH} / \mathrm{g}$. Isso indica que a extração a quente possui influência direta na qualidade da fração lipídica, pois verifica-se que, nessas condições, os óleos de peixe possuem maior facilidade de sofrer deterioração oxidativa.

\section{3 ÍNDICE DE SAPONIFICAÇÃO}

Encontram-se na Tabela 2 os índices de saponificação dos óleos brutos, obtidos de diferentes resíduos da filetagem de tilápia.

Tabela 2. Índice de saponificação ( $\mathrm{mg} \mathrm{KOH/g}$ ) dos óleos brutos de cabeça, carcaça e vísceras obtidos dos resíduos da filetagem da tilápia

\begin{tabular}{cc}
\hline Especificação das amostras & Índice de Saponificação $(\mathrm{mg} \mathrm{KOH} / \mathrm{g})$ \\
\hline Óleo de cabeça & $211,03 \pm 1,44 \mathrm{~B}$ \\
Óleo de carcaça & $210,30 \pm 0,05 \mathrm{~B}$ \\
Óleo de víscera & $142,78 \pm 0,89 \mathrm{~A}$ \\
\hline
\end{tabular}

*Médias na mesma coluna com letras diferentes são diferentes significativamente pelo teste de Tukey. 
Houve diferença significativa $(P<0,05)$ entre os índices de saponificação dos diferentes óleos e o óleo de víscera apresentou o menor índice 142,78 e o óleo da carcaça e cabeça não diferiram entre si e apresentaram valores superiores aos apresentados pelo óleo de vísceras. Dessa forma, pode-se inferir que o óleo de vísceras precisa de menor quantidade de soda, para formação de sabão, o que pode ser um limitante, já que o seu índice de acidez é o mais elevado, sendo necessário o processo de neutralização, o que pode acarretar na diminuição do rendimento do biodiesel em decorrência da grande formação de sabões.

As reações de saponificação informam o comportamento dos óleos e gorduras como no caso de estabelecer o grau de deterioração e estabilidade ou, então, verificar se propriedades dos óleos estão de acordo com as especificações e identificar possíveis adulterações (VALLE et al., 2011).

\section{4 ÍNDICE DE PERÓXIDO}

Encontram-se na Tabela 3 os índices de peróxido dos óleos brutos, obtidos de diferentes resíduos da filetagem de tilápia.

Tabela 3. Índice de peróxido (meq $\mathrm{O} 2 / \mathrm{Kg}$ ) dos óleos brutos de cabeça, carcaça e vísceras obtidos dos resíduos da filetagem da tilápia

\begin{tabular}{cc}
\hline Especificação das amostras & Índice de peróxido $\left(\right.$ meq $\left.\mathrm{O}_{2} / \mathrm{Kg}\right)$ \\
\hline Óleo de cabeça & $36,35 \pm 5,90 \mathrm{~B}$ \\
Óleo de carcaça & $34,09 \pm 3,53 \mathrm{~B}$ \\
Óleo de víscera & $38,11 \pm 7,82 \mathrm{~A}$ \\
\hline
\end{tabular}

*Médias na mesma coluna com letras diferentes são diferentes significativamente pelo teste de Tukey.

Houve diferença significativa $(P<0,05)$ entre os índices de peróxido dos diferentes óleos e o óleo de víscera apresentou o maior índice 38,11 e o óleo da carcaça e cabeça não diferiram entre si e apresentaram valores inferiores aos apresentados pelo óleo de vísceras.

O índice de peróxido permitido, para óleos de peixe $(5 \mathrm{mEq} / \mathrm{kg})$, demonstra boa qualidade do óleo que não sofreu alterações químicas oxidativas com a extração a frio e livre de peróxido (MORAIS et al., 2001). 
Isso demonstra que os óleos obtidos já se encontram em estado de degradação avançado, sendo o óleo de vísceras o mais degradado por possuir maior valor de ácidos graxos livres.

Os óleos de tilápia, por possuírem o perfil lipídico altamente insaturado, são mais susceptíveis ao processo de rancificação oxidativa em razão da fragilidade das ligações químicas que conferem menor estabilidade ao mesmo.

De acordo com Franco (1999), o índice de peróxido é um indicador sensível no estado inicial da oxidação, tendo como consequência a destruição das vitaminas lipossolúveis e dos ácidos graxos essenciais, além da formação de subprodutos com odor e sabor forte. De acordo com Valle et al. (2011), a reação entre o oxigênio e os lipídios pode ser retardada pela adição de antioxidantes que atuam rompendo a cadeia de radicais livres ou decompondo os peróxidos. Estudos realizados por Pimenta et al. (2010) mostraram que filetes de tilápia, submetidos aos tratamentos, não revelaram diferença estatística, segundo análise de variância $(P>0,05)$.

\section{5 ÍNDICE DE IODO}

Os índices de iodo dos óleos brutos, obtidos de diferentes resíduos da filetagem de tilápia, foram $95,67 \pm 8,10 \mathrm{meq} \mathrm{gI} / 100 \mathrm{~g}$ para o óleo bruto de cabeça,

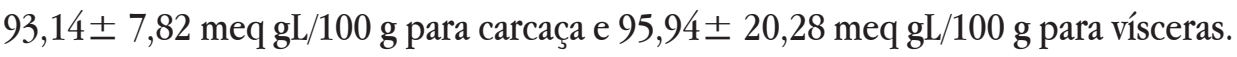

Os óleos brutos de diferentes resíduos da filetagem de tilápia não apresentaram diferença significativa para o índice de iodo. $O$ índice de iodo determina o nível de insaturação dos óleos, os valores demonstram que os óleos de tilápia possuem alto grau de insaturação se comparados aos outros óleos.

De acordo com Pimenta et al. (2010), os índices de iodo, encontrados para óleo de soja, foram de $1,37 \mathrm{mEq} \mathrm{gL} / 100 \mathrm{~g}$, para girassol 1,04 mEq gL/100 g e milho $0,81 \mathrm{mEq} \mathrm{gL} / 100 \mathrm{~g}$, o que demonstra o alto nível de instauração presente nos óleos de tilápia. Além disso, o índice de iodo pode ser utilizado para determinação da susceptibilidade dos óleos à rancidez oxidativa. 


\subsection{DENSIDADE DO ÓLEO}

Os valores de densidades dos óleos brutos, obtidos de diferentes resíduos da filetagem de tilápia, foram $0,901 \mathrm{~g} / \mathrm{cm}^{3}$ para o óleo bruto de cabeça, $0,906 \mathrm{~g} / \mathrm{cm}^{3}$ para carcaça e $0,898 \mathrm{~g} / \mathrm{cm}^{3}$ para vísceras.

A densidade dos óleos brutos de diferentes resíduos da filetagem de tilápia não apresentou diferença significativa. Analisando o índice de densidade, verifica-se que a maior concentração foi no óleo da carcaça $\left(0,906 \mathrm{~g} / \mathrm{cm}^{3}\right)$, seguido do óleo da cabeça $\left(0,901 \mathrm{~g} / \mathrm{cm}^{3}\right)$ e, por fim, do óleo da víscera $\left(0,898 \mathrm{~g} / \mathrm{cm}^{3}\right)$. A densidade é uma importante propriedade a ser estudada para o biodiesel. O objetivo deste parâmetro é restringir a utilização de algumas matérias-primas, para a produção de biodiesel, por esta característica exercer grande influência em processos como a injeção de combustível e a sua preparação para a ignição automática. O equipamento de injeção de combustível opera dentro de um sistema de medição de volume, em que uma elevada massa específica para o biodiesel resulta em entrega maior da massa de combustível. A justificativa, para que se obtenha um valor mínimo para a massa específica, está na obtenção de uma potência máxima para o motor, que usa o combustível com controle de vazão na bomba de injeção. Há, também, a necessidade de prevenção da formação de fumaça, quando este motor operar com potência máxima, o qual pode resultar em aumento na razão de equivalência na câmara de combustão (MENEZES et al., 2006).

\subsection{RENDIMENTO DO ÓLEO OBTIDO DE DIFERENTES RESÍDUOS DA FILETAGEM DE TILÁPIAS}

O rendimento dos óleos brutos, obtidos de diferentes resíduos da filetagem de tilápia, foram 9,23\% para o óleo bruto de cabeça, 6,12\% para carcaça e 34,70\% para vísceras.

A utilização da gordura resultante do processamento das vísceras demonstra uma oportunidade para o aproveitamento dos resíduos gerados com a produção de óleo da tilápia, que é um produto de alto valor agregado e com várias aplicabilidades, tais como (CUNHA et al., 2009): alimentação animal e combustível alternativo. 
Observou-se que o rendimento do óleo de vísceras é maior, pois a tilápia deposita muita gordura visceral (LANNA et al., 2004). As vísceras correspondem, aproximadamente, a 10\% do total dos resíduos, o que representa um número significativo, apesar de ser necessário realizar o processo de neutralização. Esse óleo apresenta o maior potencial para produção de biodiesel por ter rendimento maior em comparação aos outros resíduos.

\section{8 ÍNDICE DE ACIDEZ}

Encontram-se na Tabela 4 os índices de acidez dos diferentes tipos de biodiesel de vísceras de tilápia, produzidos com óleo bruto neutralizado e óleo refinado e diferentes volumes de $\mathrm{NaOH} 16 \%$.

Tabela 4. Índice de acidez de diferentes tipos de biodiesel de víscera de tilápia, produzidos com óleo bruto neutralizado e óleo refinado e diferentes volumes de $\mathrm{NaOH} 16 \%$

\begin{tabular}{cccc}
\hline \multirow{2}{*}{ Volume de $\mathrm{NaOH}(\mathrm{ml})$} & \multicolumn{3}{c}{ Tipo de óleo } \\
\cline { 2 - 4 } & 0,48 & Refinado & Médias $^{1}$ \\
\hline 5,0 & 0,48 & 0,40 & 0,44 \\
6,0 & 0,32 & 0,24 & 0,36 \\
7,0 & 0,42 & 0,22 & 0,27 \\
Médias $^{2}$ & 0,28 & 0,35 \\
\hline
\end{tabular}

${ }^{1}$ Regressão quadrática $(P<0,01) ;{ }^{2}$ As médias na linha diferem estatisticamente pelo teste $\mathrm{t}(P<0,01)$. $\mathrm{CV}=16,91 \%$.

Houve diferença significativa $(P<0,01)$, no índice de acidez entre os óleos brutos neutralizados e refinados e o índice de acidez foi menor no óleo refinado, indicando que o processo de refino é indispensável, para produção de biodiesel, de acordo com o índice de acidez.

Observou-se, ainda, que houve efeito quadrático $(P<0,01)$ do volume de $\mathrm{NaOH}$, utilizado na neutralização, independente do tipo de óleo utilizado, para produção de biodiesel, ou seja, ocorre diminuição do índice de acidez com o aumento do volume de $\mathrm{NaOH}$ empregado, até um determinado valor e, em seguida, 
esse valor parece estabilizar. Entretanto seriam necessários mais valores a esse volume para confirmar esse comportamento.

Segundo a ANP (2008), o índice de acidez do biodiesel deve ser inferior a $0,50 \mathrm{mgKOH} / \mathrm{g}$. Portanto todos os biodieseis produzidos tiveram índice satisfatório. A diferença de resultados entre o óleo bruto neutralizado e óleo refinado demonstra que o refino do óleo foi efetivo eliminando sabões presentes no óleo e neutralizando os ácidos graxos livres. Castro (2009) encontrou valores de $0,41 \mathrm{KOH} / \mathrm{g}$ para biodiesel sintetizado com base em resíduos de peixes por transesterificação metílica.

De acordo com Cunha et al. (2009), o processo de degomagem remove as impurezas como os sabões, reduzindo o consumo de álcali, no processo de neutralização, além de evitar sua precipitação, durante a estocagem do óleo. O controle de acidez do biodiesel é necessário para evitar possível corrosão em motores do ciclo diesel.

\section{9 ÍNDICE DE SAPONIFICAÇÃO}

Encontram-se na Tabela 5 os índices de saponificação dos diferentes tipos de biodiesel de vísceras de tilápia, produzidos com óleo bruto neutralizado e óleo refinado e diferentes volumes de $\mathrm{NaOH} 16 \%$.

Tabela 5. Índice de saponificação de diferentes tipos de biodiesel de víscera de tilápia, produzidos com óleo bruto neutralizado e óleo refinado e diferentes volumes de $\mathrm{NaOH} \mathrm{16 \%}$

\begin{tabular}{ccc}
\hline \multirow{2}{*}{ Volume de $\mathrm{NaOH}(\mathrm{ml})^{1}$} & \multicolumn{2}{c}{ Tipo de óleo $^{2}$} \\
\cline { 2 - 3 } & Bruto neutralizado & Refinado \\
\hline 5,0 & 100,5 & 295,3 \\
6,0 & 133,8 & 322,0 \\
7,0 & 228,0 & 337,3 \\
\hline
\end{tabular}

${ }^{1}$-As médias na linha diferem estatisticamente pelo teste de $\mathrm{t}(P<0,01) ;{ }^{2}$ Regressão linear $(P<0,01)$. $\mathrm{CV}=2,54 \%$

Houve diferença significativa $(P<0,01)$ entre o biodiesel de óleos neutralizados e óleos refinados em todos os volumes de $\mathrm{NaOH}$ avaliados e, para 
todos os volumes, o valor do índice foi maior no óleo refinado, indicando que o processo de refino é indispensável, para produção de biodiesel, de acordo com o índice de saponificação.

Ao se avaliar os diferentes volumes de $\mathrm{NaOH} 16 \%$ dentro dos óleos brutos neutralizados e refinados, observou-se efeito linear $(P<0,01)$ dos volumes, ou seja, à medida que se aumentou o volume de $\mathrm{NaOH}$ empregado, ocorreu aumento no índice de saponificação, para os dois óleos testados.

A ANP (2006) não determina um índice de saponificação para biodiesel, sendo necessária apenas a anotação dos valores. $\mathrm{O}$ aumento do volume de soda, para neutralização dos óleos, diminui a quantidade de ácidos graxos livres, reduzindo a capacidade dos óleos se transformarem em sabão, influenciando, diretamente, no rendimento do biodiesel. A presença de sabões no biodiesel tem várias consequências no motor, especialmente, para os bicos injetores (PIMENTEL et al., 2007).

De acordo com Pimenta et al. (2010), a neutralização é o processo de transformação dos triglicerídios em ácidos graxos livres, por meio do processo de saponificação. As correções dos índices de acidez podem ocorrer pelo processo de neutralização do óleo. A neutralização consiste em uma etapa do refino de óleos, em que, de acordo com O'Brien (2009), ocorre a adição de uma solução alcalina, geralmente, de hidróxido de sódio ao óleo bruto e esta solução é responsável por uma série de reações químicas e processos físicos. O álcali reage com os ácidos graxos livres formando sabões; os fosfolipídios e gomas absorvem o álcali e são degradados, absorvidos pelas gomas e solubilizados em água. Com aquecimento e tempo, o excesso de solução cáustica pode levar à saponificação do óleo neutro. Nesses processos, a concentração da solução de $\mathrm{NaOH}$, tempo de mistura, temperatura e a quantidade de excesso cáustico são fatores importantes para sua eficiência e efetividade.

\subsection{0 ÍNDICE DE PERÓXIDO}

Encontram-se na Tabela 6 os índices de peróxido dos diferentes tipos de biodiesel de vísceras de tilápia, produzidos com óleo bruto neutralizado e óleo refinado e diferentes volumes de $\mathrm{NaOH} 16 \%$. 
Tabela 6. Índice de peróxido de diferentes tipos de biodiesel de víscera de tilápia, produzidos com óleo bruto neutralizado e óleo refinado e diferentes volumes de $\mathrm{NaOH}$ $16 \%(\mathrm{CV}=23,87 \%)$

\begin{tabular}{cccc}
\hline \multirow{2}{*}{ Volume de $\mathrm{NaOH}(\mathrm{ml})$} & \multicolumn{2}{c}{ Tipo de óleo } & \multirow{2}{*}{ Médias } \\
\cline { 2 - 3 } & Bruto neutralizado & Refinado & \\
\hline 5,0 & 30,0 & 30,4 & 30,2 \\
6,0 & 26,6 & 31,8 & 29,2 \\
7,0 & 29,2 & 30,0 & 29,6 \\
\hline Médias & 28,6 & 30,7 & 29,6 \\
\hline
\end{tabular}

Não houve diferença significativa $(P>0,05)$ entre os óleos neutralizados e refinados. O índice de peróxido é importante para determinação do tempo de armazenagem e estabilidade do biodiesel (Silva et al., 1999).

A ANP (2006) não determina valores de referência para índice de peróxido. Podemos inferir que ambos os biodieseis possuem o mesmo tempo de armazenagem e estabilidade. Vale ressaltar que, de acordo com estudos realizados por Valle et al. (2011), a adição de aditivos no biodiesel protege o combustível, aumentando seu tempo de estocagem e diminui a sua susceptibilidade à degradação.

\subsection{1 ÍNDICE DE IODO}

Encontram-se na Tabela 7 os índices de iodo dos diferentes tipos de biodiesel de vísceras de tilápia, produzidos com óleo bruto neutralizado e óleo refinado e diferentes volumes de $\mathrm{NaOH} 16 \%$.

Tabela 7. Índice de iodo de diferentes tipos de biodiesel de víscera de tilápia, produzidos com óleo bruto neutralizado e óleo refinado e diferentes volumes de $\mathrm{NaOH}$ 16\% (CV=17,13\%)

\begin{tabular}{ccc}
\hline \multirow{2}{*}{ Volume de $\mathrm{NaOH}(\mathrm{ml})^{1}$} & \multicolumn{2}{c}{ Tipo de óleo $^{2}$} \\
\cline { 2 - 3 } & Bruto neutralizado & Refinado \\
\hline 5,0 & 27,5 & 30,6 \\
6,0 & 51,2 & 33,5 \\
7,0 & 57,1 & 28,4 \\
\hline
\end{tabular}

${ }^{1}$ As médias na linha diferem estatisticamente pelo teste de $\mathrm{t}(P<0,01) ;{ }^{2}$ Regressão linear $(P<0,01)$. 
Houve diferença significativa $(P<0,01)$ entre os óleos brutos neutralizados e óleos refinados em todos os volumes de $\mathrm{NaOH}$ avaliados e, no volume de $5 \mathrm{~mL}$, o valor do índice de iodo foi maior para o óleo refinado e, para os demais volumes, ocorreu o inverso. Esse comportamento pode ser explicado pela maior concentração de ácidos graxos livres no óleo bruto neutralizado quando se utilizou menor volume de $\mathrm{NaOH}$.

Quanto ao comportamento dos biodieseis, produzidos com os diferentes óleos, observou-se que, para o biodiesel de óleo bruto neutralizado, ocorreu aumento do índice de iodo à medida que se utilizou maior volume de $\mathrm{NaOH}$. Já, para o biodiesel do óleo refinado, o comportamento foi semelhante, mas a diminuição do índice ficou evidenciada, nos três volumes testados, ou seja, com aumento do volume de $\mathrm{NaOH}$ de $5 \mathrm{~mL}$ para $7 \mathrm{~mL}$, observou-se aumento gradativo com um ponto de máximo e uma queda já no nível de $7 \mathrm{~mL}$.

$\mathrm{O}$ índice de iodo não possui especificação da ANP (2006), mas ressalta-se aqui sua importância, pois ele determina o grau de instauração dos óleos. Por causa do elevado índice de iodo, por possuir alto grau de instauração, podemos inferir que, consequentemente, o índice de cetanos que equivale ao índice de octanagem é elevado, pois quanto maior o grau de instauração maior a quantidade de cetanos no biodiesel (PIMENTEL et al., 2007).

A instabilidade à oxidação é um dos maiores limitantes ao uso do biodiesel oriundos de óleos com alto índice de instauração. A menor força de ligação, presente em óleos insaturados ocasiona em menor estabilidade do biodiesel. A norma ASTM EN 14214, regulamentadora do biodiesel, na Europa, aceita valores de até $100 \mathrm{mEq}$ gL/100 g. Dessa forma, podemos considerar que os valores encontrados, para ambos os biodieseis, foram aceitáveis (EUROPEAN COMMISSION, 2007).

O índice de iodo não possui especificação da ANP (2006), mas ressalta-se aqui sua importância, pois ele determina o grau de instauração dos óleos, conforme observado, o índice de iodo apresenta valor elevado em virtude de alto grau de instauração e, consequentemente, alto índice de cetanos no biodiesel.

Estudos de Pimentel et al. (2007) mostram que a qualidade do diesel como combustível utiliza, como parâmetro principal, o número de cetano $(\mathrm{NC})$, similar ao número de octanos para a gasolina. Dessa forma, o NC indica as características 
do diesel, em relação à partida do motor. Na composição do diesel, também, aparecem compostos que possuem átomos de oxigênio, de enxofre e de nitrogênio, mas estas substâncias estão presentes em pequenas concentrações na mistura. Produzido com base no refino do petróleo, o diesel resulta da reunião de diversas misturas provenientes das diversas etapas de processamento do petróleo bruto. As proporções dessas misturas no produto final devem obedecer a especificações previamente definidas, imprescindíveis, para garantir o bom desempenho do diesel, minimizando o desgaste dos motores e de seus componentes.

\subsection{RENDIMENTO DO BIODIESEL}

Os rendimentos dos biodieseis, produzidos com base em óleos brutos neutralizados e refinados para volume de $\mathrm{NaOH}$ de $5 \mathrm{~mL}$ foram $56 \%$ e $72 \%$ respectivamente, para volume de $6 \mathrm{~mL}$ foi de $51 \%$ e $75 \%$ e para volume de 7 foi de $73 \%$ para o óleo refinado e para o óleo neutralizado não foi observado rendimento.

Em comparação entre os óleos brutos neutralizados e os óleos refinados, houve diferença, demonstrando que o refino do óleo é necessário para se obter maior rendimento de biodiesel.

No óleo bruto neutralizado com $7 \mathrm{~mL}$ de $\mathrm{NaOH}$, a reação de transesterificação não foi efetiva, ocorrendo transformação de todo óleo em sabão. Isso ocorre, pois o volume de $\mathrm{NaOH}$ empregado foi muito alto para um óleo com teor elevado de ácidos graxos livres.

O maior rendimento dos óleos refinados se justifica pela eliminação de substâncias que prejudicam a reação de transesterificação, assim como a formação de sabões e outras substâncias indesejadas no biodiesel.

Resumindo, todos os índices obtidos e regulamentados pela ANP (2006) foram considerados satisfatórios e a etapa de refino é fundamental para melhoria nos índices avaliados e maior rendimento do biodiesel. 


\section{CONSIDERAÇÕES FINAIS}

Dentre os óleos de resíduos avaliados, o que mais se adequou à produção de biodiesel em razão de alto rendimento, foi o óleo de vísceras.

Porém, para utilizá-lo para a produção de biodiesel, é necessário neutralizálo e realizar todas as etapas de refino, uma vez que, neste processamento, os índices e o rendimento foram superiores.

Ao final observamos que o biodiesel produzido com base no óleo de vísceras de tilápia, atende às normas da ANP, portanto adequado para utilização.

\section{AGRADECIMENTOS}

Os autores agradecem ao CNPq e a Capes, pelo apoio financeiro para realização deste estudo e a empresa Piscicultura Cristalina, pelo apoio logístico e por aportar os resíduos utilizados neste estudo.

\section{REFERÊNCIAS}

AGUIAR, G.P.S; GOULART, G.A.S. Produção de óleo e farinha a partir de coprodutos de pescado provenientes da bacia Tocantins-Araguaia. Revista Eletrônica Interdisciplinar, Barra do Garças, v. 1, n. 11, p. 67-71, 2014.

ANP - AGÊNCIA NACIONAL DO PETRÓLEO, GÁS NATURAL E BIOCOMBUSTÍVEIS. Resolução ANP nº 15, Brasília, DF, 17 jul. 2006.

ANP - AGÊNCIA NACIONAL DO PETRÓLEO, GÁS NATURAL E BIOCOMBUSTÍVEIS. Resolução ANP n ${ }^{\circ}$ 713/03/2008 e ANP n ${ }^{\circ} 7$ 13/03/2008, Brasília, DF, 2008.

ANP - AGÊNCIA NACIONAL DO PETRÓLEO, GÁS NATURAL E BIOCOMBUSTÍVEIS. Resolução no 25 de 2 de fevereiro de 2008, Braślia, DF, 2008. 
Practices of the American Oil Chemist's Society, Physical and Chemical Characteristics of Oils, Fats and Waxes. Section I. Ed. The AOCS Methods Editor and the AOCS Technical Department. AOCS Press, Champaign, 2004.

ARAÚJO, K.L.G.V.; EPAMINONDAS, P.S.; SILVA, M.C.D.; LIMA, A.E.A.; ROSENHAIM, R.; MAIA, A.S.; SOLEDADE, L.E.B.; SOUZA, A.L.; SANTOS, I.M.G.; SOUZA, A.G.; QUEIROZ, N. Influence of thermal degradation in the physicochemical properties of fish oil. Journal of Thermal Analysis and Calorimetry, v. 106, n. 2, p. 557-561, 2011.

BARROS, A.A.C.; WUST, E.; MEIER, H.F. Evaluate the waste fatty acid by scientific and technical study to obtain biodiesel. Revista Engenharia Sanitária Ambiental, Rio de Janeiro, v.13, n. 3, p. 255-262, 2008.

BOSCOLO, W.R.; FEIDEN, A. Industrialização de tilápias. Salvador: GFM, 2007. 272 p.

CASTRO, B.C.S. Otimização das condições das reação de transesterificação e caracterização dos rejeitos dos óleos de fritura e de peixe para obtenção de biodiesel. 2009. 119 f. Dissertação (Mestrado em Química) - Universidade Federal do Rio de Janeiro, Rio de Janeiro, 2009.

CONGRESSO BRASILEIRO DE QUÍMICA, 51, 2011, São Luís. Anais... São Luís: CBQ, 2011. CD ROM.

CONGRESSO DA REDE BRASILEIRA DE TECNOLOGIA DE BIODIESEL, 4; CONGRESSO BRASILEIRO DE PLANTAS OLEAGINOSAS, ÓLEOS, GORDURAS E BIODIESEL, 7, 2010, Belo Horizonte. Anais... Belo Horizonte: CRBTB e CBPOOGB, 2010. CD ROM.

CONGRESSO LATINO AMERICANO, 5 e CONGRESSO BRASILEIRO DE HIGIENISTAS DE ALIMENTOS, 11, 2011, Salvador. Anais... Salvador: CLA e CBHA, 2011. CD-ROM.

CUNHA, D.C.; CREXI, V.T.; PINTO, L.A.A. "Winterização" de óleo de pescado via solvente. Ciência e Tecnologia de Alimentos, v. 29, n. 1, p. 207-213, 2009. 
DABDOUB, M.J.; BRONZEL, J.L.; RAMPIN, M.A. Biodiesel: visão crítica do status atual e perspectivas na academia e na indústria. Química Nova, v. 32, n. 3, p. 776-792, 2009.

EUROPEAN COMMISSION. White paper on internationally compatible biofuel standards. Tripartite Task Force Brazil, European Union e United States of America. Brussels, 2007.

FELTER, M.M.C.; CORREIA, J.F.G.; BEIRÃO, L.H.; BLOCK, J.M.; NINOW, J.L.; SPILLER, V.R. Alternativas para a agregação de valor aos resíduos da industrialização de peixe. Revista Brasileira de Engenharia Agrícola e Ambiental, v. 14, n.6, p. 669-677, 2010.

FERNANDO, S.; KARRA, P.; HERNÁNDEZ, R.; JHA, S.K. Effect of incompletely converted soybean oil on biodiesel quality. Energy, v. 32, n.5, p. 844-851, 2007.

FUNDAÇÃO GETULIO VARGAS - FGV. O mercado do petróleo: oferta, refino e preço. Rio de Janeiro: FGV, 2012.

FRANCO, G. Tabela de Composição Química dos Alimentos. 9. ed. São Paulo: Atheneu, 1999.

GARCIA, J.C.C.; VON-SPERLING, E. Greenhouse gas emissions in the life cycle of ethanol: estimation in agriculture and industrialization stages in Minas Gerais, Brazil. Revista Engenharia Sanitária Ambiental, v. 15, n. 3, p. 217-222, 2010.

GERIS, R.; CARMO-SANTOS, N.A.; AMARAL, B.A.; MAIA, I.S.; CASTRO, V.D.; CARVALHO, J.R.M. Biodiesel de soja: reação de transesterificação para aulas práticas de química orgânica. Química Nova, v. 30, n. 5, p.1369-1373, 2007.

GUNSTONE, F.D. Vegetable oils in food technology: composition, properties and uses. Oxford: Blackwell, 2011. 337 p.

KOIKE, G.H.A.; LOPES, A.; Passarini, L.C.; CAMARA, F.T.; HILDEBRAND-JÚNIOR, L.; DAL-BEM, A.J. Emissão de gases de combustão em motor de ignição por compressão: ensaio comparativo entre diesel, biodiesel e biodiesel com injeção de etanol. Revista 
Minerva, v. 7, n. 1, p. 11-18, 2010.

KRAWCZYK, T. International news on fats, oils and related materials. Champaign: American Oil Chemists Society Press, 1996. 801p.

LANNA, E.T.; PEZZATO, L.E.; FURUYA, W.M.; VICENTINI, C.A.; CECON, P.R.; BARROS, M.M. Crude fiber and oil in diets for Nile tilapia (Oreochromis niloticus). Revista Brasileira de Zootecnia, v. 33, n. 6, p.2177-2185, 2004.

LIN, C. Y.; LIN, H. A. Diesel engine performance and emission characteristics of biodiesel produced by the peroxidation process. Fuel, v. 85, n. 3, p.298-305, 2006.

LIN, C. Y.; LIN, R. J. Fuel properties of biodiesel produced from the crude fish oil from the soapstock of marine fish. Fuel Processing Technology, v. 90, n.1, p.130136, 2009.

MENEZES, E.W.; SILVA, R.; CATALUÑA, R.; ORTEGA, R.J.C.. Effect of ethers and ether/ ethanol additives on the physicochemical properties of diesel fuel and on engine tests. Fuel, v. 85, n. 5-6, p. 815-822, 2006.

MORAIS, M.M.; PINTO, L.A.A.; ORTIZ, S.C.A.; CREXI, V.T.; SILVA, R.L.; SILVA, J.D. Estudo do processo de refino do óleo de pescados. Revista do Instituto Adolfo Lutz, v.60, n. 1, p.23-33, 2001.

O'BRIEN, R. Fats and oils: formulating and processing for applications. $3^{\text {rd }}$ ed. Boca Raton: CRC, 2009.

OLIVEIRA, A.J.; RAMALHO, J. Plano Nacional de Agroenergia 2006-2011. Ministério da Agricultura, Pecuária e Abastecimento, Secretaria de Produção e Agroenergia. 2. ed. Brasília, DF: Embrapa Informação Tecnológica, 2006.

PIMENTEL, F. J. et al. Projeto biocombustível na região norte. Brasília: SIGEOR, 2007. Sistema de Informação da Gestão Estratégica Orientada para Resultados.

REYES, J. F.; SEPULVEDA, M. A. PM-10 emissions and power of a diesel engine fueled with crude and refined biodiesel from salmon oil. Fuel, v. 85, n. 12-13, p. 1714- 
1719, 2006.

SILVA, F.A.M.; BORGES, M.F.M..; FERREIRA, M.A. Métodos para avaliação do grau de oxidação lipídica e da capacidade antioxidante. Química Nova, v. 22, n. 1, p. 94-103, 1999.

SILVA, M.J.; SOUZA, S.N.M.; SOUZA, A.A.; MARTINS, G.I.; SECCO, D. Motor gerador ciclo diesel sob cinco proporções de biodiesel com óleo diesel. Revista Brasileira de Engenharia Agrícola e Ambiental (Online), v. 16, n. 3, p. 320-326, 2012.

SILVA, P.R.F.; FREITAS, T.F.S. Biodiesel: o ônus e o bônus de produzir combustível. Ciência Rural, v.38, n.3, p.843-851, 2008.

VIDOTTI, R.M.; GONÇALVES, G.S. Produção e caracterização de silagem, farinha e óleo de Tilápia e sua utilização na alimentação animal. São José do Rio Preto, SP: Centro Avançado de Pesquisa Tecnológica do Agronegócio do Pescado Continental Instituto de Pesca - APTA/SAA, 2006.

Recebido em: 16/11/2016 Aceito em: 01/05/2017 